\title{
Thermal behaviour of procaine and benzocaine Part II: compatibility study with some pharmaceutical excipients used in solid dosage forms
}

Adriana Fuliaş ${ }^{1 \dagger}$, Ionuț Ledeți ${ }^{1 \dagger}$, Gabriela Vlase ${ }^{2 \dagger}$, Călin Popoiu ${ }^{3^{*+}}$, Alina Hegheş ${ }^{1 *+}$, Mihai Bilanin ${ }^{2 \dagger}$, Titus Vlase ${ }^{2 \dagger}$, Dorina Gheorgheosu', Marius Craina ${ }^{3^{*}}$, Simona Ardelean ${ }^{4^{*}}$, Dumitru Ferechide $5^{5^{*}}$, Otilia Mărginean ${ }^{3^{*}}$ and Liana Moş

\begin{abstract}
Background: The compatibility study of active substances with excipients finds an important role in the domain of pharmaceutical research, being known the fact that final formulation is the one administered to the patient. In order to evaluate the compatibility between active substance and excipients, different analytical techniques can be used, based on their accuracy, reproducibility and fastness.

Results: Compatibility study of two well-known active substances, procaine and benzocaine, with four commonly used excipients, was carried out employing thermal analysis (TG/DTG/HF) and Fourier Transform Infrared Spectroscopy (UATR-FT-IR). The selected excipients were microcrystalline cellulose, lactose monohydrate, magnesium stearate and talc. Equal proportion of active substance and excipients $(W / W)$ was utilized in the interaction study. The absolute value of the difference between the melting point peak of active substances and the one corresponding for the active substances in the analysed mixture, as well the absolute value of the difference between the enthalpy of the pure active ingredient melting peak and that of its melting peak in the different analysed mixtures were chosen as indexes of the drug-excipient interaction degree. All the results obtained through thermal analysis were also sustained by FT-IR spectroscopy.

Conclusions: The corroboration of data obtained by thermal analysis with the ones from FT-IR spectroscopy indicated that no interaction occurs between procaine and benzocaine, with microcrystalline cellulose and talc, as well for the benzocaine-lactose mixture. Interactions were confirmed between procaine and benzocaine respectively and magnesium stearate, and for procaine and lactose.
\end{abstract}

Keywords: Procaine, Benzocaine, Excipients, Compatibility studies, TG/DTG/HF

\footnotetext{
*Correspondence: mcpopoiu@yahoo.com; alina.heghes@umft.ro; mariuscraina@hotmail.com; simonaaardelean@yahoo.com; dferec@yahoo. com; omarginean@ymail.com; limmos2001@yahoo.com

${ }^{\dagger}$ Equal contributors

${ }^{1}$ Faculty of Pharmacy, University of Medicine and Pharmacy "Victor Babeş", Eftimie Murgu Square 2, Timişoara RO-300041, România

"Faculty of Medicine, University of Medicine and Pharmacy "Victor Babeş",

Eftimie Murgu Square 2, Timişoara RO-300041, Romania

${ }^{4}$ Faculty of Medicine, Pharmacy and Dental Medicine, "Vasile Goldis" Western

University of Arad, Henri Coanda Street 31, Arad RO-310429, Romania

${ }^{5}$ University of Medicine and Pharmacy "Carol Davila", Department of

Physiology, B-dul Eroilor Sanitari 8, Bucharest RO-050474, Romania

Full list of author information is available at the end of the article
} 


\section{Introduction}

Before or during the development of solid dosage forms, large scale development trials are normally preceded by the evaluation of possible interactions between a drug and different excipients used in the formulation process. Although, excipients are required to be medically inert, physical and chemical interactions with the active substance can occur. The screening of a novel excipient for possible incompatibilities is therefore an absolute requirement $[1,2]$.

The humidity and temperature can generate interactions between a drug and an excipient. The drugexcipient interactions can affect drug dissolution and/or bioavailability or/and their therapeutic efficacy and safety. The mechanisms by which the excipients affect the stability of drug are chemical reactions, sorption of moisture, and/or catalysis. Hence, the choice of excipients by carrying out systemic study is very important.

Thermal analytical methods are used for the determination of physical properties, kinetic properties, polymorphic forms and transitions, product stability, and excipient compatibility [3-5].

DSC, respectively DTA/HF had been shown to be an important method for the preliminary phase of any preformulation study of solid dosage form to quickly detect the interactions by comparing the thermal curves obtained for the active substance, for the excipients, and for their physical mixtures.

From the appearance, shift or disappearance of endothermic/exothermic peaks and/or variations in the corresponding enthalpy values in thermal curves of drugexcipient mixtures, it can be prove the existence of a possible interaction between the active substance and the excipient used.

A number of techniques have been used for screening of drug-excipient mixtures for interactions or incompatibilities including isothermal stress testing and thermal analysis $[4,5]$. Thermal analysis has the advantage over conventional isothermal stress testing in that long term storage of physical mixtures and chromatographic analysis are not required and only a few milligrams of sample is needed [4,6-8]. However, the technique has been criticized as being inconclusive because the moisture stress testing is usually not included and the temperature ranges, which are used, are not characteristic of normal storage conditions.

Even if it's considered a "stepping stone" in formulation, compatibility testing provide only an approximate indication for the selection/deselection of excipients, as the final composition of the pharmaceutical formulation is usually different from the one tested in the compatibility study $[9,10]$.

FT-IR spectroscopy is a simple, fast and an accurate technique for the evaluation of changes which occur during active substance - excipient mixing. The use of FT-IR relies in the analysis of spectra, by the disappearance of an absorption band, modification of its intensity or position (shifting to lower/higher wavenumbers). Also, the appearance of new absorption bands is an indisputable argument that suggests an active substance-excipient interaction. The use of spectroscopic methods, such as FTIR can bring valuable information about the mechanism of interaction, by the assignment of the bands that appear or disappear in the mixture's spectra, comparative to the ones for active substance and excipient. Compared to classic FTIR spectroscopy, where the spectra acquisition is usually carried out on a pressed-dispersion of sample in $\mathrm{KBr}$, UATR-FT-IR technique provides superior data quality combined with high reproducibility and has some advantages including: fastness, as no preparation of the samples is required, neither for the active substance, the excipient or their mixture; it is nondestructive and requires small quantities of sample which can be recovered from the surface of the spectrometer's crystal after the analysis; Also, it's accuracy is sustained by the fact that in case of classic FTIR sample preparation, the use of a mechanical press to form the pellet can induce interactions that normally does not occur in the formulation step, despite the fact that the sample is considered diluted due to the presence of $\mathrm{KBr}[10]$.

Combining DSC, respectively DTA/HF technique with a technique such as Fourier Transform Infrared (FT-IR) Spectroscopic analysis, as complementary tool, allows for detail understanding, elucidation, and interpretation of potential interactions at the molecular level.

Procaine (4-aminobenzoic acid 2-(diethyl-amino)ethyl ester, Novocain) is a local anaesthetic of the ester type which is hydrolysed in vivo to produce paraaminobenzoic acid, which inhibits the action of sulfonamides. Procaine is absorbed following parenteral administration, and can be used in combination with vasoconstrictors in order to prolong its action. Pharmaceutical administration forms contain usually 0.25 to $0.5 \%$ procaine for infiltration anaesthesia, 0.5 to $2.0 \%$ for peripheral nerve block and 10\% for spinal block [11]. Procaine is used as well in analgesic, geriatric and antiviral formulations [12].

Benzocaine (4-aminobenzoic acid ethyl ester) is considered an anaesthetic of "low solubility". This class of agents can be applied directly on injured skin and ulcerated surfaces, where they remain localized for long periods of time to produce a prolonged anaesthetic action. Benzocaine is incorporated into a large number of topical preparations [11] for local anaesthesia, such as dental sprays, ear medication or in throat anaesthetic lozenges [13] and as a desensitizer in condoms [14]. 
The present study was undertaken because the compatibility study of the selected active substances, namely procaine (PR) and benzocaine (BZ) and four excipients of common use for sustained release have not been reported earlier, to our knowledge.

For this purpose, simultaneous TG/DSC measurements and UATR-FT-IR spectroscopy measurements were carried out on each of the components, both in the pure form and the corresponding 1:1 $(w / w)$ physical mixtures. The absolute value of the difference between the melting endothermic peak temperature of pure drug and that in each analysed mixture and the absolute value of the difference between the enthalpy of the pure active ingredient melting peak and that of its melting peak in the different analysed mixtures were chosen as indexes of the drug-excipient interaction degree. As well, the analysis of FT-IR spectra sustains the interaction which took place.

\section{Experimental}

\section{Materials and samples}

The active ingredients, procaine chlorohydrate (PR) and benzocaine (BZ), were obtained from Sigma Chemical Co (lot No. 34D1214) and have an analytical purity. Excipients tested were: magnesium stearate (MS) (Union Derivan Spain), talc powder (T) (Luzenac Pharma Italy), microcrystalline cellulose (MC) (ParChem Trading Israel) and lactose monohydrate (L) (Grain Processing Corporation USA). All the compounds have an analytical purity and were used as received, without further purification.

The mixed samples consisted of equal masses of active substance and each excipient. Physical mixtures were prepared in proportion $(w / w)$ 1:1 (active substance: excipient) by simple mixing of the two substances in an agate mortar with pestle for approximately 5 minutes. The 1:1 $(w / w)$ ratio was chosen in order to maximize the probability of observing any interaction.

Thermal analysis was completed using a simultaneous TG/DTA instrument from Perkin-Elmer DIAMOND. The experiments were carried out using aluminium crucibles with approximately $7-8 \mathrm{mg}$ of the sample. For determination of the heat effects, the DTA curves (in $\mu \mathrm{V} \cdot \mathrm{mg}^{-1}$ ) were changed with the Heat Flow curves (in $\mathrm{mW} \mathrm{mg}^{-1}$ ), so that the peak area corresponds to an energy in $\mathrm{J} \mathrm{g}^{-1}$ or $\mathrm{kJ} \mathrm{mol}^{-1}$. The experiments were completed in an air atmosphere at a flow rate of $100 \mathrm{~mL}$ $\mathrm{min}^{-1}$. These were performed under non-isothermal conditions by increasing temperature from ambient up to $500^{\circ} \mathrm{C}$, at a heating rate $\beta=7^{\circ} \mathrm{C} \mathrm{min}{ }^{-1}$.

The IR spectra were carried out using a Perkin Elmer SPECTRUM 100 device in the range of 4000-600 $\mathrm{cm}^{-1}$ on an UATR device, with 16 acquisitions for each spectrum.
In order to evaluate the accuracy of the measurements, three repetitions have been done with this experimental protocol for the samples and the obtained results were comparable.

\section{Results and discussion}

\section{Thermal behaviour of the two active substances}

Thermal behaviour of active substances was studied and presented in a previous paper [15]. In order to compare the TG/DTG and HF curves obtained for PR and BZ (active substances) with the ones for active substanceexcipient mixture, the first are presented in Figure 1, but at a heating rate $\beta=7^{\circ} \mathrm{C} \mathrm{min}^{-1}$.

As mentioned in our previous paper [15], thermal decomposition of PR in an air atmosphere occurs in one single process and begins at $196.64^{\circ} \mathrm{C}$, as presented in Figure 1. The decomposition occurs in the temperature range $196.6-351.5^{\circ} \mathrm{C}$, with the mass loss of $83.57 \%$ and $T_{\text {peak } D T G}=278.8^{\circ} \mathrm{C}$.

The HF curve of procaine at $\beta=7^{\circ} \mathrm{C} \mathrm{min}{ }^{-1}$ presents, for beginning, a sharp endothermic peak at $155.8^{\circ} \mathrm{C}\left(T_{\text {onset }}=\right.$ $142.8^{\circ} \mathrm{C} ; \Delta H_{\text {fus }}=110.462 \mathrm{~J} \cdot \mathrm{g}^{-1}$ ) indicating the melting and which corresponds to the values indicated in literature $\left(155-156^{\circ} \mathrm{C}\right)$. In this temperature range, it can't be observed a mass loss on the TG/DTG curves. This process of melting is followed by another two events: the first one is an endothermic process at $279.9^{\circ} \mathrm{C}\left(T_{\text {onset }}=238.3^{\circ} \mathrm{C}\right.$; $\left.\Delta H_{f u s}=243.31 \mathrm{~J} \cdot \mathrm{g}^{-1}\right)$ and the last one has an exothermic nature with a maximum at $342.6^{\circ} \mathrm{C} \quad\left(T_{\text {onset }}=302.8^{\circ} \mathrm{C}\right.$; $\left.\Delta H_{\text {fus }}=-144.79 \mathrm{~J} \cdot \mathrm{g}^{-1}\right)$.

In the case of benzocaine, the thermal behaviour is similar. The first thermal event for the $\mathrm{BZ}$ is an endothermic one, without mass loss, and represents the melting of this active substance $\left(H F_{\text {peak }}=90.1^{\circ} \mathrm{C} ; T_{\text {onset }}=\right.$ $\left.76.23^{\circ} \mathrm{C} ; \Delta H_{\text {fus }}=107.94 \mathrm{~J} \cdot \mathrm{g}^{-1}\right)$. This value is the same with the melting point mentioned in literature $\left(88-90^{\circ} \mathrm{C}\right)$. The following thermal event take place in the temperature range $135.9-247^{\circ} \mathrm{C}$ with a mass loss percentage $\Delta \mathrm{m}=99.9 \%$ $\left(H F_{\text {peak }}=245 \cdot 2^{\circ} \mathrm{C}\right)$. The experimental determined values for the thermal parameters are similar to the ones obtained in our previous study [15], the differences being attributed to a different heating rate $\left(\beta=7^{\circ} \mathrm{C} \cdot \mathrm{min}^{-1}\right.$, instead of $\beta=10^{\circ} \mathrm{C}$. $\min ^{-1}$ ) (see Table 1).

\section{Compatibility study with the excipients by thermal analysis}

The DSC and thermogravimetrical curves of individual excipients which were used in the compatibility study are presented in Figure 2.

The thermoanalytical curves for the analyzed mixtures (binary systems: active substance + excipient) are presented in Figure 3.

The thermal curves of benzocaine and procaine respectively, MC and their physical mixture (Figure 3 (a) 
and (e)) are almost superimposable. It wasn't observed any changes in the values of the process' temperatures ( $T_{\text {onset }}$ ot $\left.T_{\text {peak }}\right)$, nor disappearance and appearance of supplementary peaks in the case of the mixtures with MC. The melting behaviour of the drugs (PR and $\mathrm{BZ}$ ) is not affected by the presence of MC. It may be concluded that there is no interaction between the two active substances and $\mathrm{MC}$ under the testing conditions.

Another used excipient is talc, which possess a higher thermal stability, as can be seen in Figure 2 (c). According to V. Balek et al. [16], the first mass loss for a sample of talc is observed by TG in the range $900-1050^{\circ} \mathrm{C}$ and characterized the loss of structural water due to dehydroxylation of $\mathrm{Mg}_{3} \mathrm{Si}_{4} \mathrm{O}_{10}(\mathrm{OH})_{2}$ and accompanied by the formation of enstatite $\left(\mathrm{MgSiO}_{3}\right)$ and silica [17].

As expected, in the thermoanalytical curves of talc, no peaks were observed in the analysed range $50-550^{\circ} \mathrm{C}$ (Figure 2 (c)). For the two mixtures with this excipient, the endothermic peak which corresponds to the melting process of $\mathrm{PR}$ and $\mathrm{BZ}$, respectively was well preserved at 154 and $88^{\circ} \mathrm{C}$, respectively in the HF curve of the active substance-talc mixture.

The thermoanalytical curves of magnesium stearate (Figure 2 (a)) present a lot of thermal events. The HF curve of this excipient shows three principal events: the first correspond to the dehydration process from range $75-102^{\circ} \mathrm{C}$; the
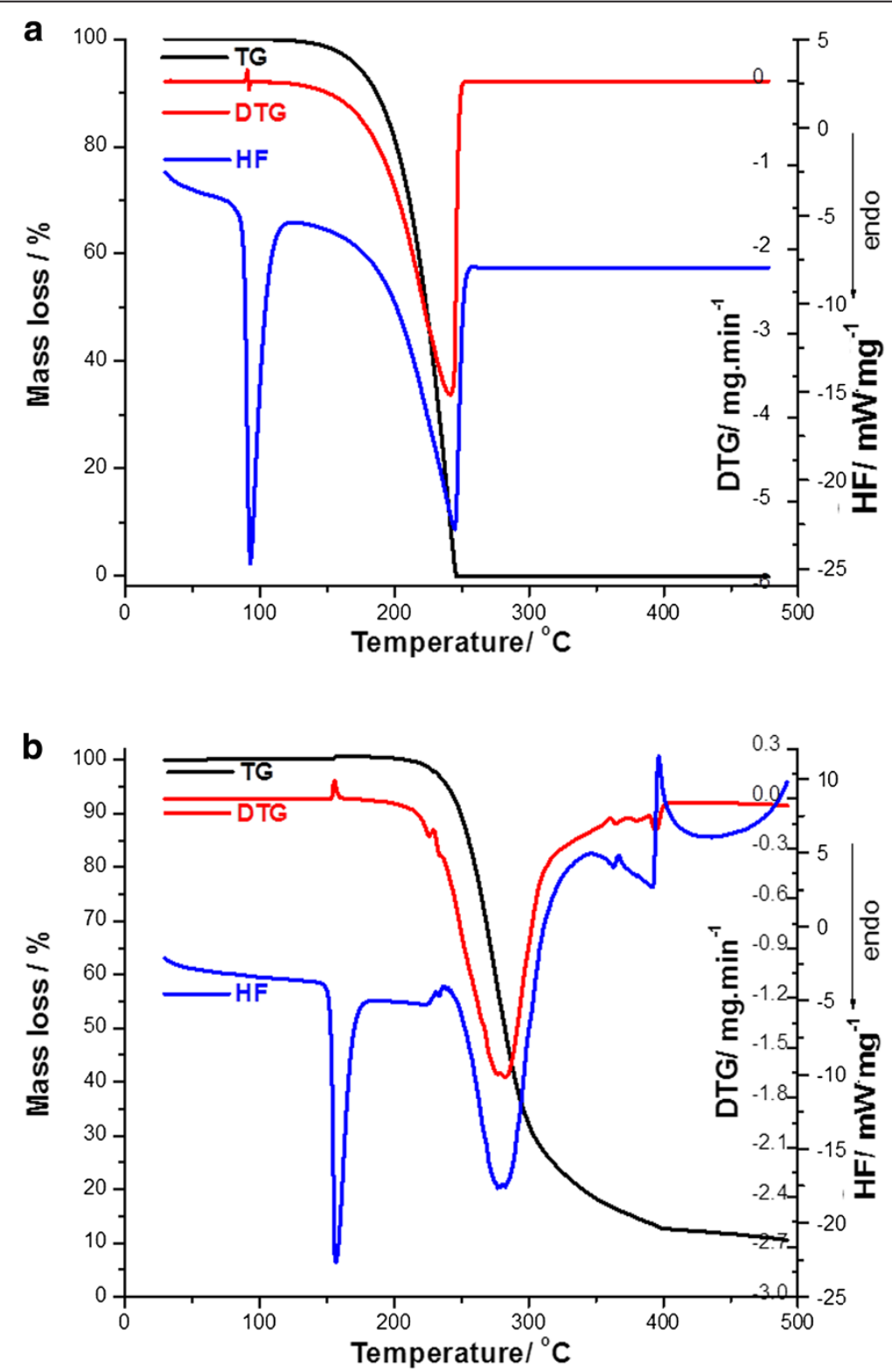

Figure 1 The thermoanalytical curves TG/DTG/HF obtained in air at $\beta=7^{\circ} \mathrm{C} \min ^{-1}$ for the analysed active substances: (a) BZ and (b) PR. 
Table 1 Thermoanalytical data of the two active substances and the used excipients

\begin{tabular}{|c|c|c|c|c|c|}
\hline \multirow[t]{2}{*}{ Substance } & \multicolumn{2}{|c|}{ TG/DTG curves } & \multicolumn{2}{|c|}{ HF curves } & \multirow{2}{*}{$\begin{array}{l}\text { Nature of the } \\
\text { process }\end{array}$} \\
\hline & $\begin{array}{c}\mathrm{T}_{\text {onset }} / \\
{ }^{\circ} \mathrm{C}\end{array}$ & $\begin{array}{l}T_{\text {peak }} \\
\text { DTG } /{ }^{\circ} \mathrm{C}\end{array}$ & $\begin{array}{c}\mathrm{T}_{\text {onset }} / \\
{ }^{\circ} \mathrm{C}\end{array}$ & $\begin{array}{l}\mathrm{T}_{\text {peak }} \\
\mathrm{DSC}^{\circ} \mathrm{C} \mathrm{C}\end{array}$ & \\
\hline Procaine & 194.5 & 281 & $\begin{array}{l}148 \\
240\end{array}$ & $156 ; 279$ & $\begin{array}{c}\text { melting; } \\
\text { decomposition }\end{array}$ \\
\hline Benzocaine & 130 & 241 & $\begin{array}{l}77 \\
147\end{array}$ & $90 ; 246$ & $\begin{array}{c}\text { melting; } \\
\text { decomposition }\end{array}$ \\
\hline$M C$ & $\begin{array}{l}40 \\
295\end{array}$ & $55 ; 354$ & 50 & 125 & $\begin{array}{l}\text { dehydratation; } \\
\text { decomposition }\end{array}$ \\
\hline L & $\begin{array}{l}75 \\
218\end{array}$ & $\begin{array}{c}86 ; 158 ; \\
317\end{array}$ & $\begin{array}{l}254 ; \\
367\end{array}$ & $270 ; 409$ & $\begin{array}{l}\text { dehydratation; } \\
\text { decomposition }\end{array}$ \\
\hline MS & $\begin{array}{l}50 \\
280\end{array}$ & $78 ; 362$ & 50 & 117 & $\begin{array}{l}\text { dehydratation; } \\
\text { decomposition }\end{array}$ \\
\hline Talc & -- & -- & -- & -- & -- \\
\hline
\end{tabular}

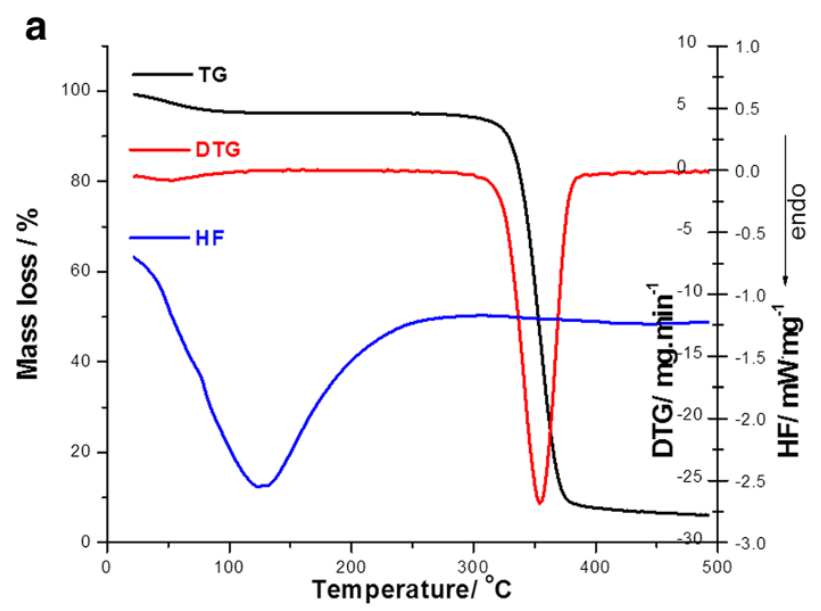

C

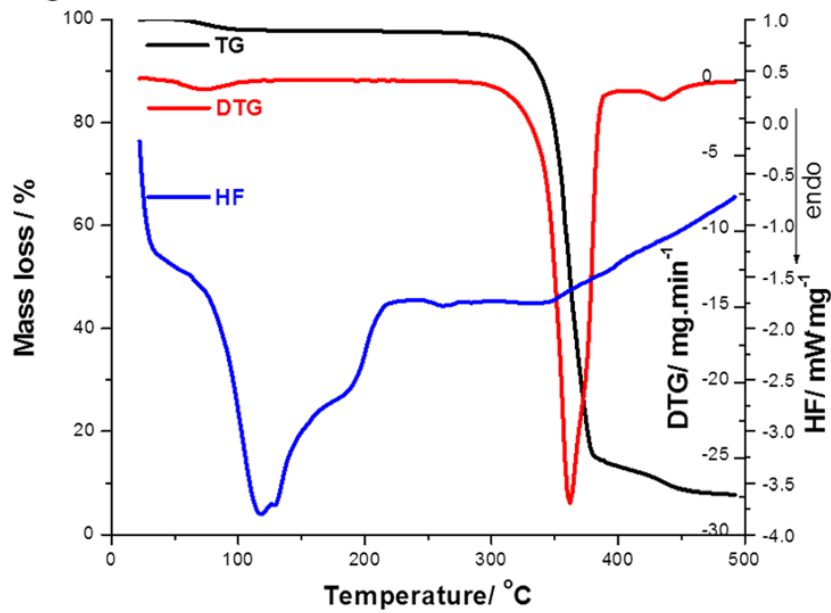

second event $\left(119-130^{\circ} \mathrm{C}\right)$ indicates the melting point for palmitic acid salt and stearic acid salt with magnesium, respectively [18], being known that pharmaceutical MS used as excipient is a mixture of different magnesium salts of some fatty acids, the mainly proportions being the salts of stearic and palmitic acid. Being a mixture, this excipient melts in an extent temperature range which can vary between 117 and $150^{\circ} \mathrm{C}$, but a high purity form of this excipient was reported having the melting at $128 \pm 2^{\circ} \mathrm{C}$ [19].

The HF curves of benzocaine and procaine, respectively with magnesium stearate reveals a well-defined interaction with this excipient which were evidenced by the shift of the endothermic melting peaks with more than $2^{\circ} \mathrm{C}$ compared to that of pure active substance.

Due to the comparison of the TG/DTG/HF curves of the two active substances, MS and their binary mixtures, it can be concluded that the stability of the analysed b

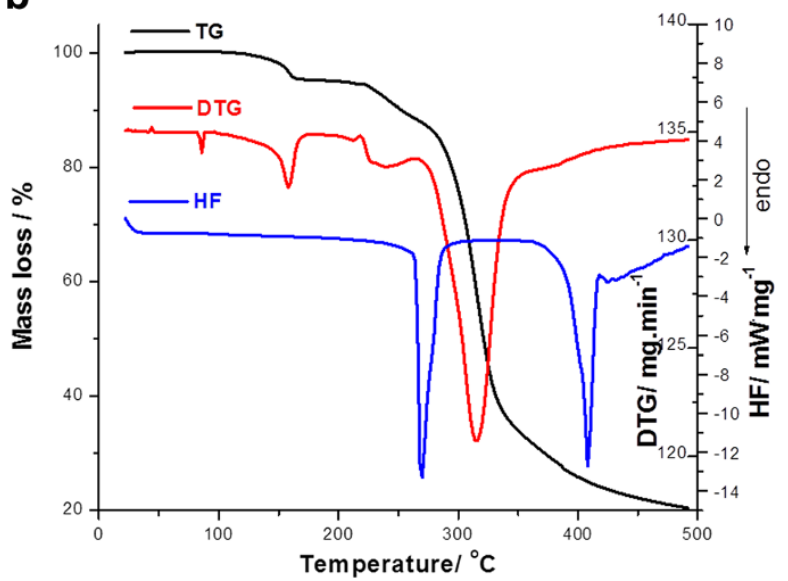

d

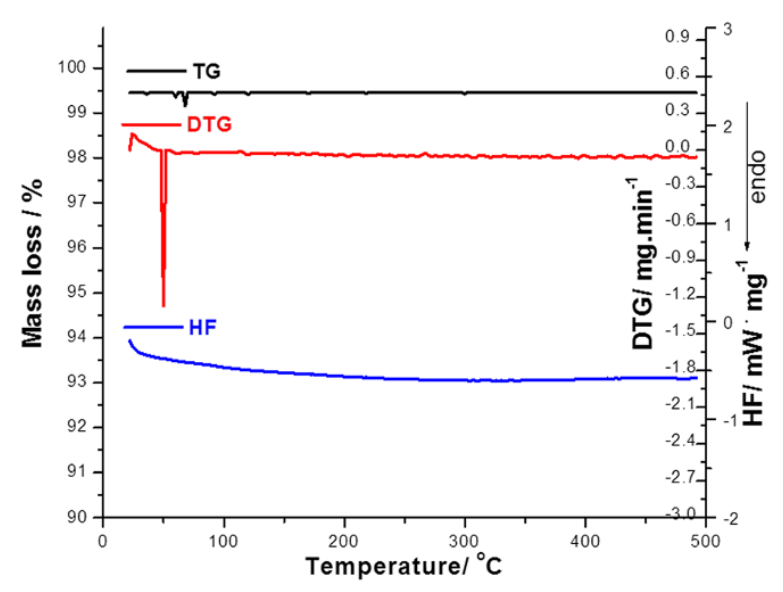

Figure $2 \mathrm{TG} / \mathrm{DTG} / \mathrm{HF}$ curves in air at $7^{\circ} \mathrm{C} \mathrm{min}^{-1}$ for: (a) magnesium stearate (MS); (b) lactose monohydrate (L); (c) talc (T); (d) microcrystalline cellulose (MC). 


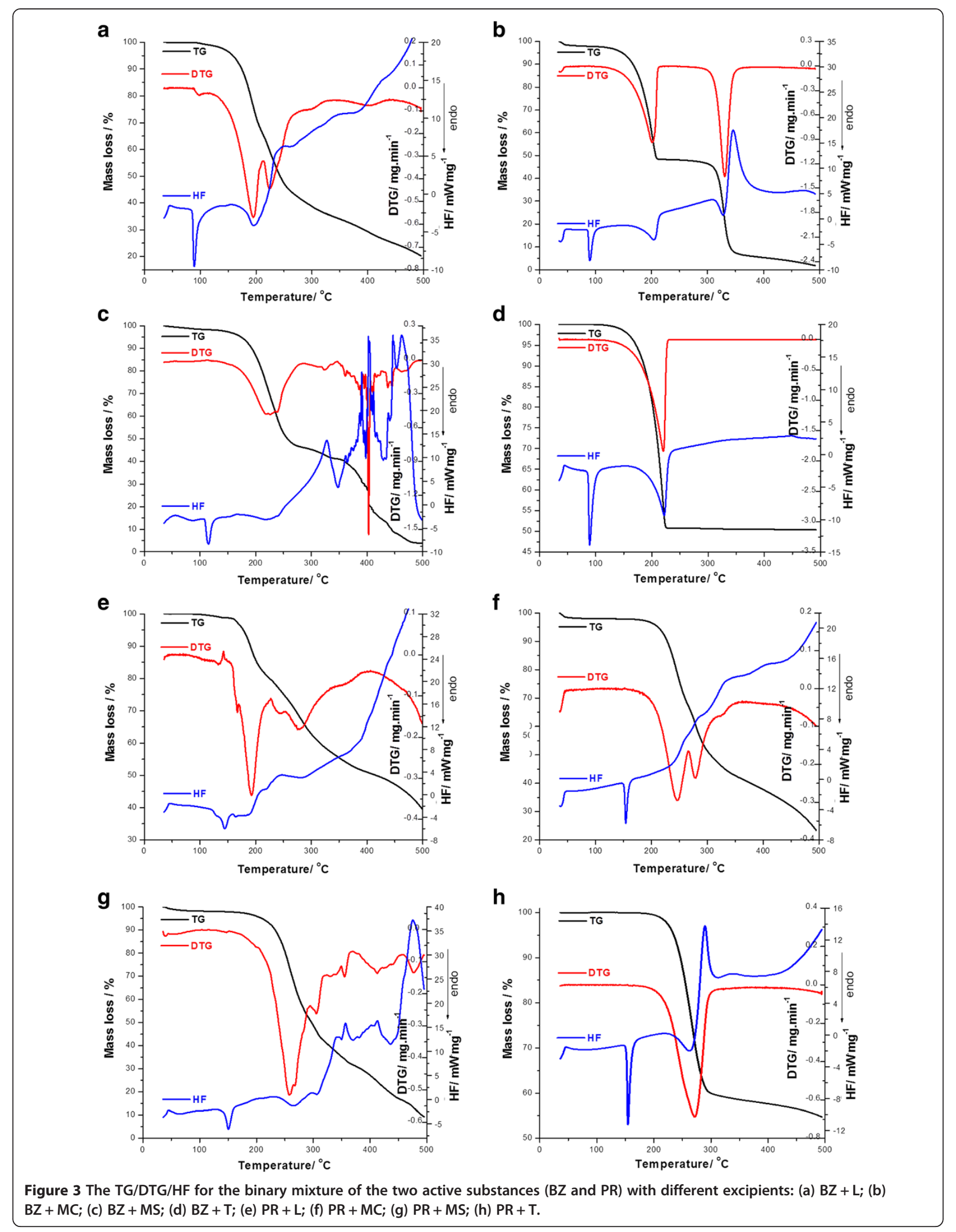


substances (PR and BZ) in these mixtures is changed. Thus, it can be said that this excipient increased the thermal degradation of procaine. The TG curve of the 1:1 (w:w) binary mixture between PR and MS, shown in Figure $3(\mathrm{~g})$, when compared to the TG curve of the pure PR and to the TG curve of the pure MS (shown in Figures 1 and 2(a)), confirms the reaction between the drug and the excipient, evidenced by the premature mass loss. The thermal decomposition begins at a lower temperature value $\left(T_{\text {onset }} D T G=163^{\circ} \mathrm{C}\right.$ for the mixture with MS) and the maximum of DTG peak takes place at $259^{\circ} \mathrm{C}$. Another reason for an accelerated degradation is the value of $\Delta m$ (\%) which is greater than $50 \%$, the expected value due to the fact that the mixture is in proportion $(w / w)$ 1:1. Given these changes, the thermal stability of PR in the presence of MS was reduced, due to the possible chemical interaction between the active substances and excipient under heating. In the case of $\mathrm{BZ}$ mixture with MS, the thermal degradation of the active substance begins at a higher temperature value ( $T_{\text {onset }}$ $D T G=137^{\circ} \mathrm{C}$ ) and the value for the melting temperature is increased with $\approx 25^{\circ} \mathrm{C}$.

The same thing was noticed in the HF curve of the binary mixture of procaine with lactose monohydrate (Figure 3 (f)) that presented a shift of the procaine' melting peak from 144 to $154^{\circ} \mathrm{C}$ suggesting a drug-excipient interaction upon mixing and heating treatment. Another difference consists in the fact that the DSC patterns of the binary mixture of PR with lactose monohydrate showed peaks which occurred at different temperature in addition to those recorded for the individual substances (Table 2). It can be seen from this table that in the case of PR-L mixture, an additional prominent DTG peak appeared at $T_{\text {peak } D T G}=191^{\circ} \mathrm{C}\left(T_{\text {onset }}=142^{\circ} \mathrm{C}\right)$ and the main DTG peak at $T_{\text {onset }}=190^{\circ} \mathrm{C}$ in the case of pure
PR degradation shifted to higher temperature of $T_{\text {onset }}=$ $226^{\circ} \mathrm{C}$, probably due to the interaction of lactose monohydrate with this active substance.

The values of $T_{\text {peak }}, T_{\text {onset }}$ for DTG and HF curves, the mass loss percentage $(\Delta m)$ and the heat of fusion value $\left(\Delta H_{f}\right)$ of melting event of procaine and benzocaine respectively, in various excipient mixtures, are presented in Table 2.

\section{Compatibility study with the excipients by UATR-FT-IR spectroscopy}

The FT-IR spectra of excipients (Figure 4a), and the ones of active substances (PR and BZ) superposed with the studied mixtures (Figure $4 \mathrm{~b}-\mathrm{e}$ ) are presented in order to confirm the interaction previously mentioned.

By the analysis of FTIR spectrum of pure PR, one can notice the presence of several distinctive bands, characteristic to vibrational modes of functional groups, as follows: a doublet consisting of two sharp $\mathrm{N}-\mathrm{H}$ stretching bands at 3345 and $3314 \mathrm{~cm}^{-1}$, a $-\mathrm{NH}_{2}$ scissoring band at $1604 \mathrm{~cm}^{-1}$ and $-\mathrm{NH}_{2}$ wagging and twisting bands in the $850-750 \mathrm{~cm}^{-1}$ spectral range. The band around $3200 \mathrm{~cm}^{-1}$ can be assigned to ammonium ions (due to the fact that procaine was used as a chlorohydrate) The spectrum also shows a C-N stretching band in 1360-1250 $\mathrm{cm}^{-1}$ range characteristic for aromatic amines. The presence of a tertiary amino group is sustained by the $-\mathrm{N}-\mathrm{CH}_{2}$ stretching band around $1170 \mathrm{~cm}^{-1}$. The two most polar bonds in esters are the $\mathrm{C}=\mathrm{O}$ and $\mathrm{C}-\mathrm{O}$ respectively, which produce distinctive bands in the spectrum around $1700 \mathrm{~cm}^{-1}$ and $1200 \mathrm{~cm}^{-1}$, respectively. Being an aromatic ester, it is expected that aromatic $\mathrm{C}=\mathrm{O}$ stretching appears at lower wavenumbers than the ones characteristic for aliphatic ones (which absorb near $1750 \mathrm{~cm}^{-1}$ ), in this case at $1692 \mathrm{~cm}^{-1}$. On the other hand,

Table 2 Thermoanalytical data of active substances and their physical mixtures

\begin{tabular}{|c|c|c|c|c|c|c|}
\hline \multirow[t]{2}{*}{ Samples } & \multicolumn{2}{|c|}{ HF } & \multirow[t]{2}{*}{$\Delta \mathrm{H}_{\text {fusion }} / \mathrm{J} \mathrm{g}^{-1}$} & \multicolumn{2}{|c|}{ DTG } & \multirow[t]{2}{*}{$\Delta \mathrm{m} / \%$} \\
\hline & $\mathrm{T}_{\text {onset (fusion) }} /{ }^{\circ} \mathrm{C}$ & $\mathrm{T}_{\text {peak (fusion) }} /{ }^{\circ} \mathrm{C}$ & & $\mathrm{T}_{\text {onset }} /{ }^{\circ} \mathrm{C}$ & $\mathrm{T}_{\text {peak DTG }} /{ }^{\circ} \mathrm{C}$ & \\
\hline \multicolumn{7}{|c|}{ Active substance } \\
\hline BZ & $77 ; 147$ & $90 ; 246$ & 107.95 & 130 & 241 & 99.9 \\
\hline$P R$ & $148 ; 240$ & $156 ; 279$ & 110.47 & 194.5 & 281 & 90 \\
\hline \multicolumn{7}{|c|}{ Drug/excipient } \\
\hline$B Z+M C$ & $84 ; 161 ; 309$ & $90 ; 204 ; 327$ & 50.23 & 110 & 201 & $55 ; 45$ \\
\hline$B Z+L$ & $77 ; 153$ & $88 ; 196$ & 48.52 & $87 ; 122$ & $99 ; 195 ; 226$ & $3 ; 52$ \\
\hline$B Z+M S$ & 103 & 113.5 & 37.18 & 137 & 227 & $5 ; 50$ \\
\hline $\mathrm{BZ}+\mathrm{T}$ & $78 ; 159$ & $88 ; 222$ & 54.70 & 120 & 220 & 50 \\
\hline$P R+M C$ & 146 & 154 & 50.89 & $173 ; 266$ & $247 ; 280$ & 65 \\
\hline$P R+L$ & 114 & 144 & 29.35 & $142 ; 226$ & $191 ; 278$ & 50 \\
\hline$P R+M S$ & 133 & 149 & 32.12 & 163 & 259 & 70 \\
\hline$P R+T$ & $144 ; 219$ & $154 ; 263 ; 288$ & 56.78 & 180 & 273 & 45 \\
\hline
\end{tabular}




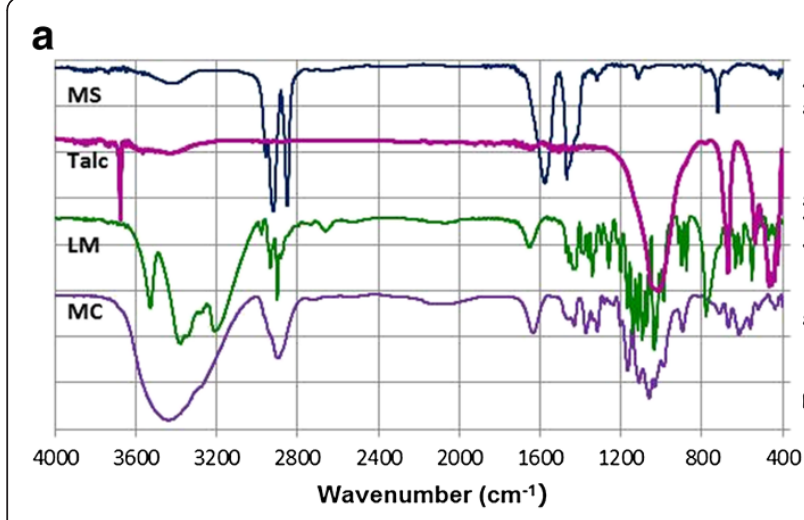

b

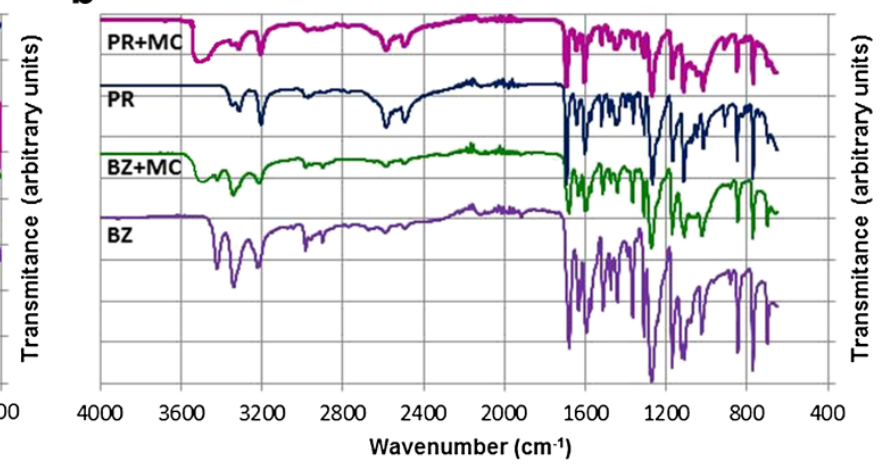

C

d
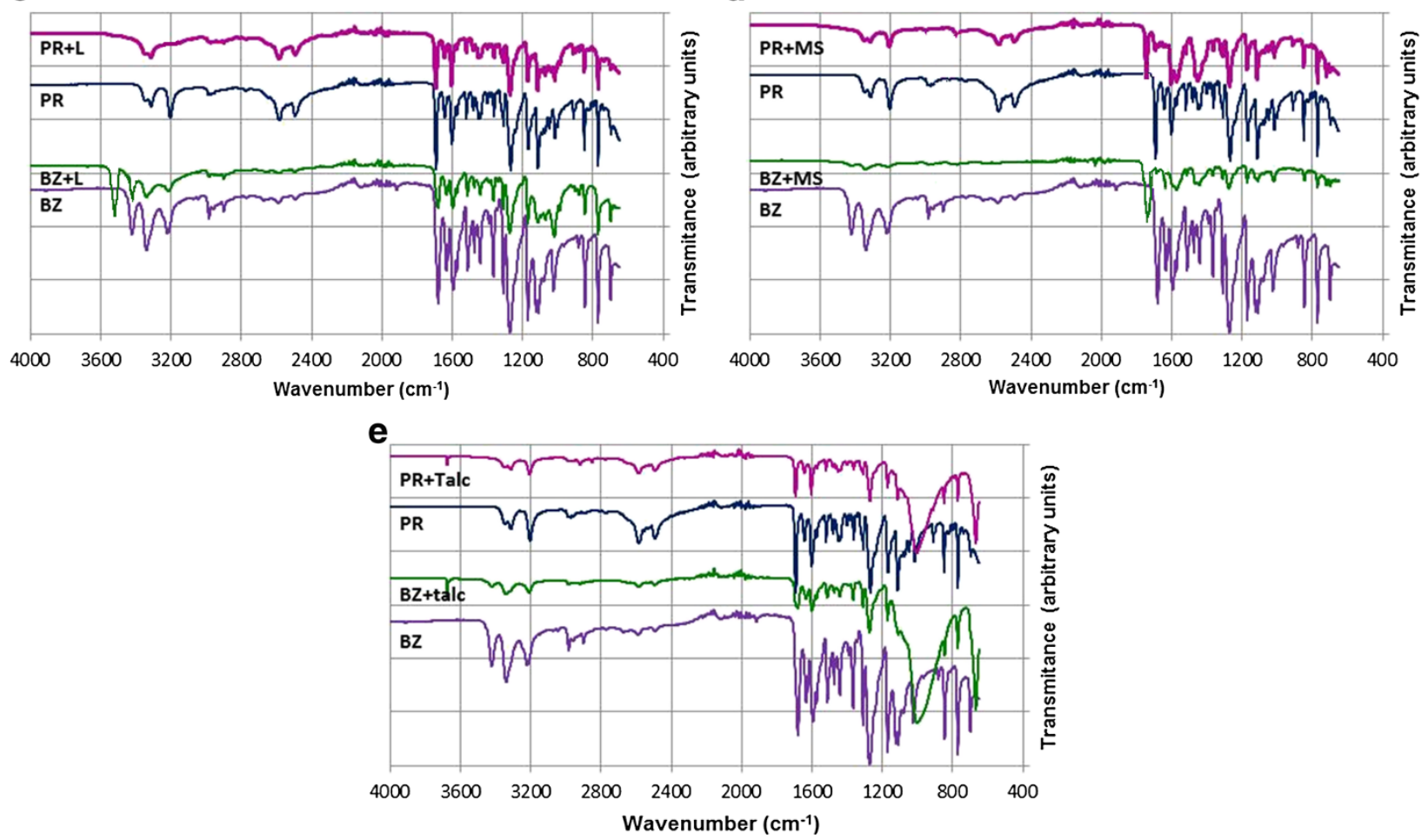

Figure 4 FT-IR spectra of: pure excipients (a); PR and BZ with MC (b); PR and BZ with L (c); PR and BZ with MS (d); PR and BZ with T (e).

the $\mathrm{C}-\mathrm{O}$ stretching can be attributed to the intense band around $1250 \mathrm{~cm}^{-1}$ [20].

The similarity of benzocaines' structure to the one of procaine lead to the conclusion that IR spectra presents several similarities, namely: a doublet consisting of two sharp N-H stretching bands at 3340 and $3320 \mathrm{~cm}^{-1}$, a $\mathrm{NH}_{2}$ scissoring band at $1594 \mathrm{~cm}^{-1}$ and $\mathrm{NH}_{2}$ waging and twisting bands in the $850-750 \mathrm{~cm}^{-1}$ spectral range. The spectrum also shows a C-N stretching band in 1366$1240 \mathrm{~cm}^{-1}$ range characteristic for aromatic amines. The $\mathrm{C}=\mathrm{O}$ and $\mathrm{C}-\mathrm{O}$ bonds in an aromatic ester produce distinctive bands at $1679 \mathrm{~cm}^{-1}$ and $1253 \mathrm{~cm}^{-1}$, respectively.

The FTIR bands characteristic to $\mathrm{C}-\mathrm{C}, \mathrm{C}-\mathrm{H}$ or aromatic ring does not present interest in our study due to the fact that in formulation step, their breaking is highly improbable. According to this, the analysis of FTIR spectra will be focused on the modification of characteristic bands for $\mathrm{N}-\mathrm{H}$ and carbonyl groups.

\section{The analysis of $B Z$ and PR mixtures with $M C$}

Characteristic vibration bands for functional groups (amine, ester) for both active substances can be identified even in the FTIR spectrum of mixtures. No bands suffer modification of intensity or shifting to increased or decreased wavenumbers. The FTIR spectra of PR and $\mathrm{BZ}$ mixtures with $\mathrm{MC}$ show the presence of the characteristic band for the $\mathrm{O}-\mathrm{H}$ stretching of hydroxyls from $\mathrm{MC}$ at $3450 \mathrm{~cm}^{-1}$ as a broad signal. The $\mathrm{C}=\mathrm{O}$ 
and $\mathrm{C}-\mathrm{O}$ bands appear at the same wavenumber as in the case of pure PR and BZ. In this case, FTIR spectroscopy confirms that no interaction occurs (Figure 4b).

\section{The analysis of $B Z$ and $P R$ mixtures with $L$}

By comparative analysis of FTIR spectrum for BZ and $\mathrm{BZ}+\mathrm{L}$, once can notice that no alteration of the spectra occurs. It can be considered that the spectrum of $\mathrm{BZ}+\mathrm{L}$ mixture is a superposing of both $\mathrm{BZ}$ and $\mathrm{L}$ spectra, leading to the conclusion that no interaction occurs. On the other hand, surprisingly, the spectrum of PR $+\mathrm{L}$ mixture is different than the superposition of the ones for pure compounds. As can be seen, the characteristic $\mathrm{O}-\mathrm{H}$ stretching from lactose around $3550 \mathrm{~cm}^{-1}$ disappear, as well the band characteristic for ammonium ion from procaine $\left(3200 \mathrm{~cm}^{-1}\right)$. By the FTIR spectroscopy analysis one can confirm that no interaction occurs between $\mathrm{BZ}$ and $\mathrm{L}$, but an incompatibility occurs for $\mathrm{PR}+\mathrm{L}$ mixture. A tentative explanation for the interaction of procaine with lactose can be attributed to the fact that under heating, procaine hydrochloride decomposes with the release of $\mathrm{HCl}$. It is known that lactose is a disaccharide derived from the condensation of galactose with glucose, by a $\beta-1 \rightarrow 4$ glycosidic linkage. The presence of $\mathrm{HCl}$ creates an acidic medium, which can lead to lactose hydrolysis with the formation of the corresponding monosaccharides or their degradation products.

\section{The analysis of BZ and PR mixtures with MS}

MS is the only excipient from the ones' studied that is incompatible with both active substances. Pure MS presents two intense absorption bands at $1566 \mathrm{~cm}^{-1}$ and $1466 \mathrm{~cm}^{-1}$, respectively, corresponding to asymmetric stretch of the $\mathrm{COO}^{-}$anion, and at higher wavenumber $\left(2917 \mathrm{~cm}^{-1}\right.$ and $\left.2850 \mathrm{~cm}^{-1}\right)$ the ones corresponding to vibrations of $\mathrm{C}-\mathrm{H}$ bonds. The analysis of FTIR spectra lead to the conclusion that the main modification in the molecular structure of both PR and BZ took place at ester carboxyl moiety. In both cases, a significant shifting of bands to higher wavenumbers occurs. In the case of $\mathrm{PR}+\mathrm{MS}$, the wavenumber is shifted up to $1722 \mathrm{~cm}^{-1}$, and for $\mathrm{BZ}+\mathrm{MS}$, is shifted up to $1730 \mathrm{~cm}^{-1}$. Literature indicates that stretching of aliphatic $\mathrm{C}=\mathrm{O}$ occurs in spectral range $1750-1730 \mathrm{~cm}^{-1}$ [20]. In this case, a possible explanation for this shifting could be the fact that the esteric group suffers a chemical modification, with the transformation of the aromatic ester into an aliphatic one due to the presence of stearate anion or leading to the formation of $p$-aminobenzoic acid, due to the hydrolysis of ester by the presence of $\mathrm{HCl}$. Surprisingly, in the FTIR spectra of mixtures, bands corresponding to
$\mathrm{COO}^{-}$anion from MS still appears, leading to the conclusion a part of MS remains unmodified in the mixture.

\section{The analysis of $\mathrm{BZ}$ and PR mixtures with $\mathrm{T}$}

For both mixtures, $\mathrm{PR}+\mathrm{T}$ and $\mathrm{BZ}+\mathrm{T}$, the FTIR spectra can be considered as a superposition of the individual ones without modification of bands' characteristics. The FTIR spectrum of $\mathrm{T}$ contains fewer bands than the ones of other excipients, due to the fact that has a simple structure comparative to the ones of organic molecules. The main bands that appear in the FTIR spectrum of T are the ones at $3675 \mathrm{~cm}^{-1}$ (stretching vibration of $\mathrm{O}-\mathrm{H}$ bond from $\mathrm{Si}-\mathrm{O}-\mathrm{H}$ moiety), at $1050 \mathrm{~cm}^{-1}$ (stretching vibration of O-Si bond from $\mathrm{Si}-\mathrm{O}-\mathrm{H}$ moiety) and at $675 \mathrm{~cm}^{-1}$ and $525 \mathrm{~cm}^{-1}$ (asymmetrical vibrations for $\mathrm{Si}-\mathrm{O}$ bond) [20]. In the case of binary mixtures, the bands appear unmodified compared to pure T. On the other hand, no modifications are noticed for the bands corresponding to PR and BZ. It can be stated that both active substances are compatible with $\mathrm{T}$ and no interaction occurs.

\section{Conclusions}

The results obtained from this study confirm that the thermoanalytical methods (TG/DTG/HF) and FTIR spectroscopy can be used as simple and accurate methods in the evaluation of the compatibility between PR and BZ respectively and the four tested excipients.

No interaction was observed between procaine and benzocaine, with microcrystalline cellulose and talc, as well for the $\mathrm{BZ}+\mathrm{L}$ mixture. This fact is confirmed by FTIR spectroscopy were nor disappearance or appearance of supplementary bands in the case of the mixtures with $\mathrm{MC}, \mathrm{T}$ and $\mathrm{L}$. It may be concluded that there is no interaction between the two active substances (PR and $\mathrm{BZ}$ ) and $\mathrm{MC}$ and $\mathrm{T}$ under the testing conditions, nor for BZ and $\mathrm{L}$.

From the results of the Heat Flow and thermogravimetrical studies, an interaction was confirmed between PR and BZ respectively and MS, and for PR and L. All these experimental observations are sustained by the use of UATR-FT-IR spectroscopy as a complementary tool for compatibility testing.

\section{Competing interests}

The authors declare that they have no competing interests.

\section{Authors' contributions}

$A F, I L, G V, C P$ and $A H$ formulated the research idea and planned the experiment. The experimental setup was designed by all co-authors. MB, TV had carried out the collection of data. MC and CP had prepared the figures. $A F, I L, G V$ and $A H$ had processed results and tables and had finalized the manuscript. OM, DG, DF and LM have further commented and reviewed. All authors participated in the article's design and coordination and helped to draft the manuscript. All authors read and approved the final manuscript.

\section{Acknowledgements}

This work was supported by a grant from the University of Medicine and Pharmacy "Victor Babeş" Timişoara (Grant 15,250/19.12.2012 to A.F.).

\section{Author details}

"Faculty of Pharmacy, University of Medicine and Pharmacy "Victor Babeş", Eftimie Murgu Square 2, Timişoara RO-300041, România. ${ }^{2}$ Research Centre for 
Thermal Analysis in Environmental Problems, West University of Timişoara, Pestalozzi Street 16, Timişoara RO-300115, Romania. ${ }^{3}$ Faculty of Medicine, University of Medicine and Pharmacy "Victor Babeş", Eftimie Murgu Square 2, Timişoara RO-300041, Romania. ${ }^{4}$ Faculty of Medicine, Pharmacy and Dental Medicine, "Vasile Goldis" Western University of Arad, Henri Coanda Street 31, Arad RO-310429, Romania. ${ }^{5}$ University of Medicine and Pharmacy "Carol Davila", Department of Physiology, B-dul Eroilor Sanitari 8, Bucharest RO-050474, Romania.

Received: 11 May 2013 Accepted: 15 August 2013

Published: 20 August 2013

\section{References}

1. Stulzer HK, Rodrigues PO, Cardoso TM, Matos JSR: Compatibility studies between captopril and pharmaceutical excipients used in tablets formulations. J Therm Anal Calorim 2008, 91:323-328.

2. Nunes RS, Semaan FS, Riga AT, Cavalheiro ETG: Thermal behaviour of verapamil hydrochloride and its association with excipients. J Therm Anal Calorim 2009, 97:349-353.

3. Fuliaş A, Vlase $T$, Vlase $G$, Doca N: Thermal behaviour of cephalexin in different mixtures. J Therm Anal Cal 2010, 99:987-992.

4. Fuliaş A, Ledeți I, Vlase G, Vlase T: Physico-chemical solid-state characterization of pharmaceutical pyrazolones: an unexpected thermal behaviour. J Pharm Biomed Anal 2013, 81-82:44-49.

5. Vikarm Singh A, Kanta Nath L: Evaluation of compatibility of lamivudine with tablet excipients and a novel synthesized polymer. J Mater Environ Sci 2011, 2(3):243-250.

6. Vlase $\mathrm{T}$, Vlase $\mathrm{G}$, Doca N: Thermal behaviour of some phenitoine pharmaceuticals. J Therm Anal Calorim 2008, 92:259-262

7. Rezende RLO, Santoro MIRM, Matos JR: Stability and compatibility study on enalapril maleate using thermoanalytical techniques. J Therm Anal Calorim 2008, 93(3):881-886

8. Kandarapu R, Grover V, Chawla HPS, Garg S: Evaluation of compatibility of ketorolac tromethamine with selected polymers and common tablet excipients by thermal and isothermal stress testing. STP Pharm Sci 2001, 11:449-457.

9. Monkhouse DC, Maderich A: Whither compatibility testing? Drug Dev Ind Pharm 1989, 15:2115-2130

10. Liltorp K, Gorm Larsen T, Willumsen B, Holm R: Solid state compatibility studies with tablet excipients using non thermal methods. J Pharm Biomed Anal 2011, 55(3):424-428.

11. Brunton LL, Lazo JS, Parker KL: Goodman and Gilman's - the pharmacological basis of therapeutics. 11th edition. New York: McGraw-Hill Medical Publishing Division Company, Inc; 2006:380.

12. Negwer M, Scharnow HG: Organic-chemical drugs and their synonyms, Volume 1.8 extensively enlargedth edition. Weinheim: Wiley-VCH verlag $\mathrm{GmbH} ; 2001: 869$.

13. Negwer M, Scharnow HG: Organic-chemical drugs and their synonyms, Volume 1.8 extensively enlargedth edition. Weinheim: Wiley-VCH verlag $\mathrm{GmbH} ; 2001: 358$

14. Spencer SE, Kim SY, Kim SB, Schug KA: Matrix-assisted laser desorption/ ionization-time of flight-mass spectrometry profiling of trace constituents of condom lubricants in the presence of biological fluids. Forensic Sci Int 2011, 207(1-3):19-26.

15. Fulias A, Vlase G, Grigorie C, Ledeți I, Albu P, Bilanin M, Vlase T: Thermal behaviour studies of procaine and benzocaine. J Therm Anal Calorim 2013, 113:265-271.

16. Balek V, Šubrt J, Pérez-Maqueda LA, Beneš M, Bountseva IM, Beckman IN, Pérez-Rodríguez $\mathrm{JL}$ : Thermal behaviour of ground talc mineral. J Mining Metallurgy 2008, 44(B):7-17.

17. Aglietti EF: The effect of dry grinding on the structure of talc. App/ Clay Sci 1994, 9:139-147.
18. Wypych G: Handbook of antiblocking, release, and slip additives. Toronto: ChemTec Publishing; 2005:243.

19. Devi MV, Babu PSSK: Drug-excipient interaction studies on enalapril maleate. Int J Pharm Excipients 2000, 2:153-158.

20. Silverstein RM, Webster FX, Kiemle D: Spectroscopic identification of organic compounds. New York: John Wiley \& Sons Ltd; 2005.

doi:10.1186/1752-153X-7-140

Cite this article as: Fuliaş et al:: Thermal behaviour of procaine and benzocaine Part II: compatibility study with some pharmaceutical excipients used in solid dosage forms. Chemistry Central Journal 2013 7:140

\section{Publish with ChemistryCentral and every scientist can read your work free of charge \\ "Open access provides opportunities to our colleagues in other parts of the globe, by allowing anyone to view the content free of charge." W. Jeffery Hurst, The Hershey Company. \\ - available free of charge to the entire scientific community \\ - peer reviewed and published immediately upon acceptance \\ - cited in PubMed and archived on PubMed Central \\ - yours - you keep the copyright \\ Submit your manuscript here: \\ http://www.chemistrycentral.com/manuscript/<smiles>c1ccccc1</smiles> \\ Chemistry Central}

